\title{
The Ancients, the Vulgar, and Hume's Skepticism
}

\author{
By Maria Magoula Adamos*
}

\begin{abstract}
Section III of part IV of Book I of Hume's Treatise entitled "Of the ancient philosophy" has been virtually ignored by most Hume scholars. Although philosophers seem to concentrate on sections II and VI of part IV and pay little or no attention to section III, the latter section is paramount in showing how serious Hume's skepticism is, and how Hume's philosophy, contrary to his intention, is far removed from "the sentiments of the vulgar".

In this paper I shall first explore Hume's view on ancient philosophy as it is presented in section III, and I shall particularly focus on his discussion of identity and simplicity of bodies. Second, I shall argue that Hume's account of identity and simplicity in terms of qualities is at best unsatisfactory. Finally, I shall try to show that Hume's advice to hold a "moderate" skepticism cannot be taken seriously. On the contrary, Hume seems to hold an "extravagant" skepticism, since he claims that there is a contradiction between our most fundamental natural beliefs, as well as between our natural beliefs and philosophical reasoning.
\end{abstract}

\section{Hume's Account of Identity}

The section "Of the Ancient Philosophy" is just another application of Hume's naturalistic approach to the birth of ancient philosophical theories. According to Hume, our ideas of bodies are nothing but collections "form'd by the mind of the ideas of the several distinct sensible qualities, of which objects are compos'd, and which we find to have a constant union with each other"(Hume, p. 219). However, in our everyday experience we regard, mistakenly, these distinct sensible qualities as "One thing, and as continuing the Same under very considerable alterations"(Hume, p. 219). We therefore attribute (falsely) to the "acknowledged composition" of perceptions simplicity and to the variation of them identity. But this is a contradiction, Hume tells us, since on the one hand our senses perceive totally distinct and different qualities, and on the other hand, we believe that the combination of these discrete parts possesses a unity and simplicity which endure over time. This is the main reason, according to Hume, that the ancients resorted to the notions of substance or prime matter. They merely wanted to provide a philosophical system that would salvage us, the vulgar, from our contradictions. Although

*Associate Professor of Philosophy, Georgia Southern University, USA 
according to Hume the ancients' ascriptions of substance and prime matter are capricious and false, they, too, arise from fundamental principles of human nature, and as such they are worthy of study: “...I am persuaded there might be several useful discoveries made from a criticism of the fictions of the antient philosophy, concerning substances...which however unreasonable and capricious, have a very intimate connexion with the principles of human nature" (Hume, p. 219).

Why do we "almost universally fall into such evident contradictions?"(Hume, p. 219) In order to answer this question Hume discusses our idea of "identity of bodies". According to Hume, when ideas of the discrete yet successive qualities of objects are united together by a very close relation, then the mind is "fooled", so to speak, and considers the succession of different and separate qualities as just one, "continuous" thing:

...[T]he mind, in looking along the succession, must be carry'd from one part of it to another by an easy transition, and will no more perceive the change, than if it contemplated the same unchangeable object. This easy transition is the effect or rather the essence of relation; and the imagination readily takes one idea for another where their influence on the mind is similar; hence it proceeds that any such succession of related qualities is readily consider'd as one, continu'ed object, existing without any variation. (Hume, p. 220) [My italics].

Here Hume uses his typical associationist approach. That is, the uninterrupted progress of ideas deceives the mind and for that reason it ascribes an identity to the changeable "succession of connected qualities". So, when the object is observed continuously through a succession of small changes, there is an easy transition from one idea to another and we believe that we have the same (self-identical) object, which endures over time.

Let us assume for the sake of the argument that Hume is right concerning the easy transition of ideas when they are in a close relation. What happens when the relation between the ideas is not close any more? In such a case, says Hume, although small changes over time may go unnoticed, if we observe the object in two different periods of time then the changes become evident and the mind becomes aware of them: "the variations, which were insensible when they arose gradually, do now appear of consequence, and seem entirely to destroy the identity" (Hume, p. 220). This is where the contradiction starts: on the one hand, the mind, viewing the changes of the object, is reluctant to ascribe identity to it; on the other hand, it has a strong propensity to attribute identity to the object despite the changes it has observed. In order to solve the contradiction imagination (our deus ex macina) "feigns" something "unknown and invisible which continues the same under all these variations; and this unintelligible something it calls a substance, or original and first matter"(Hume, p. 220). 
So, according to Hume, the vulgar is in contradiction when she ascribes identity to objects. If this is the case, I do not see what is wrong with the philosophical system, since to all appearances it seems to actually salvage the vulgar system from the contradiction by creating the notions of substance and prime matter. For, according to Hume this is exactly what the philosophical system ought to be doing; namely, to "approach nearer to the sentiments of the vulgar" (Hume, p. 222). Moreover, if the identity claim of the vulgar is unavoidable as Hume seems to suggest, then it follows that the postulation of first matter by the ancients may also be unavoidable.

But perhaps Hume's argument of identity would fare better if we adopt his (presumably correct) theory of the mind. If Hume is right that only perceptions of sensible qualities really exist, the only thing that the vulgar (and the ancient philosopher) is truly aware of is her own perception of qualities --not the object that has such qualities. As we have seen, when the vulgar does not observe any changes in the qualities [of the object] --when there is an easy transition of the mind -- she easily ascribes identity to it. Hume's theory of perception can easily accommodate this.

A much more important question is what happens when the vulgar recognizes the changes in the qualities of the object? Does she still maintain that the object has the same qualities in order to ascribe identity to it? Or does she posit a substance or prime matter in order to maintain that the qualities are the same? That is, when the vulgar realizes that the qualities of the object have changed, doesn't she recognize that she made a faulty judgment? We have to notice here that Hume's argument of identity in section "Of the Ancient Philosophy" is given in terms of qualities, and not in terms of constancy and continued existence. Therefore, even if we adopt Hume's theory of perception, the different qualities that the object acquires through time do destroy identity and it seems that nothing can salvage the vulgar's identity claim. What is more, even if we postulate a 'substance' or 'prime matter' in this case, we are still having the same problem. For instance, if the qualities Q (of an "object" P), say an oak tree, are observed in two different and distant periods of time $t$ and $t$ ', the qualities $\mathrm{Q}$ [of $\mathrm{P}$ ] at $\mathrm{t}$ would be completely different from the qualities $\mathrm{Q}^{\prime}$ at time $t^{\prime}$. In this case, the vulgar would have to admit that $P$ at $t$ becomes $\mathrm{P}^{\prime}$ at $\mathrm{t}^{\prime}$. (Assuming again that Hume's theory about the independent existence of perceptions is true). If Hume is right that only perceptions of qualities exist, then, even if the vulgar "feigns" a notion of substance, she cannot salvage her claim that the qualities remained the same over the two time periods ( $\mathrm{t}$ and $\mathrm{t}$ '). The qualities of $\mathrm{P}$ have changed and it seems nothing can make them identical. But then, since the postulation of substance cannot salvage the claim that $\mathrm{P}$ and $\mathrm{P}^{\prime}$ are qualitatively identical, our inclination to ascribe identity cannot explain why we (or the ancients) should feign a substance. It seems that unless we already have a notion of substance in which all these different qualities inhere, our identity claim concerning different qualities does not really work. In other words, it seems that unless we have already a notion of substance, which enables us to say that the object remains the same despite the change of its qualities, the postulation of substance, after we notice that the qualities are 
different, does not help our identity claim. For such a postulation will not make us think that the qualities we perceived as different are now the same. In order for our identity claim to work, we need to first form a notion of simplicity of substance so that we can form a notion of an object, and then will we be able to ascribe identity to it. This will enable us to say that the object we observed at time $t$ is the same as the object that we observed at time $t^{\prime}$.

If I am right, then Hume's explanation of how we, the vulgar, ascribe identity to objects cannot stand. That is, even if we accept his theory of perceptions, Hume's analysis is unsatisfactory, since it does not explain how our postulation of substance or prime matter solves the contradictions Hume accuses us of. This in turn shows two things: 1) Hume is wrong in his criticism of ancient philosophical theories' postulation of substance, since they give a better account of identity than Hume, and at the same time are able to "remain close to the sentiments of the vulgar." 2) The vulgar is not only left with contradictory beliefs, but also with desperation and distress; for, even if she adopts the judicious philosophical standpoint (such as Hume's) she will never be able to get rid of or at least explain her erroneous judgments. Indeed, Hume's unsatisfactory analysis leads us to extravagant skepticism, since it shows that not only is there no justification for our natural beliefs, but also that we are not in a position to give an explanation of them, even if we adopt Hume's judicious philosophical standpoint.

\section{Hume's Account of Simplicity}

Is Hume's discussion of "simplicity of substances" perhaps more convincing? Hume uses an associationist approach here as well. When the mind observes an "object" whose co-existent parts are closely related to one another by a "strong relation", it considers the object as one, single thing: "The connection of parts in the compound object has almost the same effect, and so unites the object within itself, that the fancy feels not the transition in passing from one part to another. Hence, the colour, taste, figure, solidity, and other qualities, combin'd in a peach or melon, are conciev'd to form one thing"(Hume, p. 221). However, here, unlike the case of identity, the mind is not aware of the error --at least within the vulgar standpoint:

\footnotetext{
${ }^{1}$ Terence Penelhum in his paper "Hume on Personal Identity" also argues that Hume's account of identity fails to capture the way we, the vulgar, think. More importantly, he claims that Hume is mistaken when he ascribes contradictory beliefs and errors to the vulgar. Penelhum believes that if someone is making a mistake about identity, it is Hume. Yet, Penelhum fails to notice whether we are in error or not in our identity descriptions depends on the ontology that we subscribe to. That is, only if we reject Hume's theory of perceptions the vulgar is not involved in contradictions. If, however, we adopt Hume's view of perceptions having separate existences, then Hume is right in ascribing contradictions and errors to the vulgar. For, if only perceptions of qualities exist, then the vulgar faces the contradiction of believing that the qualities of the object have changed and at the same time remained the same. Penelhum's discussion fails to take into account Hume's theory of perceptions, and as a result, it fails to show that Hume is mistaken in thinking that we are involved in contradictions.
} 
Whenever it [the mind] views the object in another light, it finds that all these qualities are different, and distinguishable, and separable from each other; which view of things being destructive of its primary and more natural notions, obliges the imagination to feign an unknown something or original substance and matter as a principle of union of cohesion among these qualities and as what may give the compound object a title to be call'd one thing, notwithstanding its diversity and composition. (Hume, p. 221) [italics mine]

Let us assume that we are able to observe the world in "another light", as Hume suggests. Then, again, we are faced with contradictions. If we adopt the vulgar standpoint, we see simple things whose parts form a united whole. However, if we adopt the philosophical standpoint, then we realize that the object is made of several parts, which are distinct and loose. In order to free itself from the contradictions, imagination feigns [again] "an unknown something, or original substance and matter, as a principle of union or cohesion among these qualities, and as what may give the compound object a title to be call'd one thing, notwithstanding its diversity and composition"(Hume, p. 221). ${ }^{1}$ So, according to Hume, the mind postulates an "original" substance in order to salvage itself from the contradictions of perceiving the separate existences of the different qualities [of the object], and its simplicity [of the object] simultaneously.

Unfortunately this argument will be shown to be problematic as well. Let us agree with Hume (for the sake of argument) that sensible qualities are indeed separate existences. Suppose that the color of an apple and the sweet taste of the apple are distinct and separate existences in the sense that at some time in the future the color may remain the same, while the sweet taste disappears and vice versa. However, this does not show that the red color of the apple (at that moment) can exist by itself, separate from the taste or the other qualities of the apple. Indeed, in section VII of part I even Hume seems to deny the possibility of distinct and separate existence of qualities. In this section Hume seems to claim that color and shape are just distinctions of reason:

... [W] hen a globe of white marble is presented, we receive only the impression of a white colour dispos'd in a certain form, nor are we able to separate and distinguish the colour from the form. But observing afterwards a globe of black marble and a cube of white

\footnotetext{
${ }^{1}$ If Hume thinks that viewing the object in another light is only possible within the philosophical standpoint, then he does not show nor does he explain how we, the vulgar, form the idea of a single, whole, thing. From what he says in this passage it seems that what comes naturally to us is the idea of oneness and simplicity of the object and only upon reflection are we able to see that we are mistaken in thinking that the object we observe forms a unified whole. But, one would expect Hume to say the opposite; namely, that we first perceive the distinct and separable qualities of the object, and, then, because the mind becomes uneasy and has the propensity to ascribe oneness and wholeness to the object the imagination feigns a notion of substance in which all the qualities inhere.
} 
and comparing them with our former object, we find two separate resemblances, in what formerly seem'd, and really is, perfectly inseparable. After a little more practice of this kind, we begin to distinguish the figure from the colour by a distinction of reason; that is, we consider the figure and colour together, since they are in effect the same and indistinguishable; but still view them in different aspects, according to the resemblances, of which they are susceptible. When we wou'd consider only the figure of the glove of white marble, we form in reality an idea both of the figure and colour, but tacitly carry our eye to its resemblance with the globe of black marble: And in the same manner when we wou'd consider its colour only, we turn our view to its resemblance with the cube of white marble (Hume, p. 25).

Here it seems that the qualities of the apple, like those of the marble, cannot be distinct and separate existences --in the sense that they can exist without each other-- after all. For, the color of the apple and the taste of the apple are only distinctions of reason, and as such they cannot be distinct separate existences. But, if this is the case, then Hume's analysis of simplicity of substance is, again, unsatisfactory. For, if Hume is not able to show that perceptions of qualities have separate existences and are therefore distinguishable, then it seems that we, the vulgar, are not committing errors when we perceive the object as a unified whole. This in turn, can explain how we ascribe identity to an object over time. That is, we first form the notion of simplicity of substance where all these qualities inhere, and then we are able to say that an object remains the same even if its qualities have changed.

In his quest to answer why we fall to contradictions regarding the simplicity of substances, Hume tells us that the answer lies in the habit of the imagination. Surprisingly, he equates our habit of inferring from causes to effects to that of inferring a substance or accidental matter: "the same habit which makes us infer a connexion betwixt cause and effect makes us here infer a dependence of every quality on the unknown substance"(Hume, p. 222). But, if this is the case, then, one wonders, why Hume makes such a big fuss about ancient philosophy, claiming that these philosophers are worse than children and poets? If the same habit, which makes us infer from causes to effects makes us ascribe a "dependence of every quality on the unknown substance", then the conclusion of the ancients comes naturally, and hence they should not be blamed. Moreover, if the habit that makes us infer a "dependence of every quality on the unknown substance" is the same as that which makes us infer from cause to effect, then it follows that both are emerging from the same principles of the imagination. ${ }^{1,2}$

\footnotetext{
${ }^{1}$ However, in the beginning of the section "Of the Modern Philosophy", where Hume distinguishes between the two principles of imagination, he takes that these habits (i.e. the habit of inferring from cause to effect and that of inferring a dependence of every quality on substance) are entirely different, coming from different "principles of imagination".
} 
One may ask, if Hume holds that imagination is the only "judge" in all philosophical systems, then how can he justify his own philosophical theory? His answer rests on the opening paragraph of the section "Of the Modern Philosophy". In a moment of self-criticism Hume confesses: "But here it may be objected, that the imagination, according to my own confession, being the ultimate judge of all systems of philosophy, I am unjust in blaming the antient philosophers for making use of that faculty, and allowing themselves to be entirely guided by it in their reasonings"(Hume, p. 225). Hume's answer to this objection is that there is a distinction between two principles of imagination:

In order to justify myself, I must distinguish in the imagination betwixt the principles which are permanent, irresistible, and universal; such as the customary transition from causes to effects, and from effects to causes: And the principles, which are changeable, weak, and irregular; such as those I have just now taken notice of [concerning substances, substantial forms, accidents and occult qualities]. The former are the foundation of all our thoughts and actions, so that upon their removal human nature must immediately perish and go to ruin. The latter are neither unavoidable to mankind, nor necessary, or so much as useful in the conduct of life. (Hume, p. 225).

Hence, our belief in causes according to Hume is universal and unavoidable, whereas the ancient belief in substance is neither useful nor necessary in our everyday experience. That is, Hume will not create a philosophical system according to his fancy.

Thus, according to Hume, the first set of reasoning (that is our belief in causes) is completely unproblematic. However, the second set is not only problematic but also useless. ${ }^{1}$ Now, even if we grant that the ancients' postulation of substance and prime matter is totally unnecessary and problematic, then what Hume says about identity in section II of part IV of the Treatise, seems rather odd, for it is highly dubious that we, the vulgar, think the way that Hume describes. We, like the ancient philosophers, take it that there is something more in the world other than our perceptions of qualities. That is, we, the vulgar, think that the world consists in tangible, material objects, which remain the same over time. It follows that there are not only the ancient philosophers who ascribe substance to our external world, but also the vulgar. Consequently, the ancient "fiction" of substance belongs to the first kind of principles of imagination Hume mentions, because it seems to be "unavoidable,

\footnotetext{
${ }^{2}$ It is worth noting that for Hume the philosophical system is always dependent on the vulgar system, since it does not have any authority of its own. One would expect the philosophical system to abandon the ideas of identity and simplicity since there are not sufficient grounds for even holding these ideas. However, this is not the case. Of course, the reason for this, according to Hume, is that nature renders the task of abandoning the ideas of identity and simplicity impossible.

${ }^{1}$ This directly contradicts what Hume had claimed in the previous section, (i.e. our belief in substance and our belief in causes are stemming from the same principles of imagination).
} 
irresistible and universal". Again, Hume seems to be further from the sentiments of the vulgar than the ancients.

\section{Hume's Scepticism}

A true philosopher according to Hume, is characterized by a moderate scepticism. Hume's advice to a "true philosopher" is to escape first from a false philosophy and confess that "we have no idea or power or agency, separate from the mind" concerning the necessary connections in nature. For, "what can be imagin'd more tormenting, than to seek with eagerness, what for ever flies us; and seek for it in a place, where 'tis impossible it can ever exist?" (Hume, p. 223). Hence, the philosopher should attain "true philosophy" by returning back to the situation of the vulgar and regard "all these disquisitions with indolence and indifference"(Hume, p. 223).

However, Hume seems to hold an "extravagant" skepticism, for as we have seen, according to him when our natural beliefs are subjected to a critical reflection they lose any kind of justification whatsoever. Therefore, Hume's advice to hold "moderate skepticism" cannot be taken seriously. Indeed, Hume's insufficient account of identity leads to the most "extravagant skepticism", and I do not see how Hume can escape the charge of contradiction. That is to say, if Hume professes to be a "true philosopher", then his conclusions must come after a critical reflection. If Hume, who is a "true philosopher" is not able to give a sufficient explanation of our natural belief in identity, then it seems that nothing can really lead us to the truth. But, this conclusion (again) exceeds the limits of "moderate scepticism". 1

\footnotetext{
${ }^{1}$ Those who advocate a naturalistic interpretation of Hume might disagree with me at this point. Barry Stroud in his paper "Hume's Scepticism: Natural Instincts and Philosophical Reflection" believes that Hume's mitigated scepticism should not be understood as a set of doctrines or truths: "It is something we can find ourselves with, or a state we can find ourselves in, when the reflections leading to excessive scepticism have been tempered or mitigated by our natural inclinations. So mitigated scepticism is not just a qualified or watered-down version of the complete or excessive scepticism, which Hume arrives at in his uncompromising, negative philosophizing. In particular, it is not the thesis that we can never be absolutely certain of anything but can at most have beliefs which are only probable" (p.34). Even if Stroud is right about his interpretation of Hume's mitigated (or moderate) scepticism, it does not undermine my claim that given Hume's conclusion such skepticism cannot be held. For, how can the philosopher who realizes that all our beliefs are in an outright error return to the situation of the vulgar and not worry about it? Maybe Hume is right that nature renders the task of living according to our skeptical conclusions impossible. Yet, living in accordance with our nature while knowing that none of our beliefs is true or justified, leads to despair and anxiety, for it shows that nothing we can do will overcome our faulty judgments. In other words, even if Hume means by "adhering to moderate skepticism" that we, as philosophers, should return to the situation of the vulgar, I do not think that it is possible to take his advice seriously. Once we realize that our beliefs are faulty and/or unjustified, it seems that nothing can help us escape from the net of extravagant skepticism.
} 


\section{Conclusion}

In summary this paper is an attempt to show that Hume's account of identity in terms of qualities is inadequate. Hume's argument concerning the "uselessness" of the ancient philosophy's postulation of substance and prime matter fails to convince us. If indeed Hume believes that true philosophy should be nearer to the "sentiments of the vulgar" it seems that ancient philosophy fits exactly with this characterization, since it allows for a more plausible account of identity than Hume's. For, we, the vulgar, believe that the external world consists of simple, tangible material things, which remain the same over time. Accordingly, Hume's call to hold a "moderate skepticism" cannot convince us, since Hume himself seems to hold an "extravagant" skepticism by presenting the fundamental contradiction between our natural beliefs as well as between our natural beliefs and philosophical reasoning. Besides, Hume's insufficient explanation of identity and simplicity of substances does not leave any room for 'moderate' scepticism whatsoever.

\section{Bibliography}

Fogelin, R. J. (1985). Hume's Skepticism in the Treatise of Human Nature. London: Routledge \& Kegan Paul.

Hume, D. (1978). Treatise of Human Nature. L.A. Selby-Bigge (ed.). Oxford: Oxford University Press.

Penelhum, T. (1968 [1888]). 'Hume on Personal Identity'. In: V.C. Chappell (ed.) Hume. New York: Anchor Books.

Smith, N. (1941). The Philosophy of David Hume. London: Macmillan.

Strawson, G. (2011). The Evident Connexion: Hume on Personal Identity, Oxford: Oxford University Press.

Stroud, B. (1977). Hume. London: Routledge \& Kegan Paul.

(1991)."Hume's Scepticism: Natural Instincts and Philosophical Reflection" in Philosophical Topics. 19: 1: 15-40. 
